\title{
Nuclear receptors and clearance of apoptotic cells: stimulating the macrophage's appetite
}

\section{Noelia A-Gonzalez * and Andrés Hidalgo}

Department of Epidemiology, Atherothrombosis and Imaging, Fundación Centro Nacional de Investigaciones Cardiovasculares, Madrid, Spain

\section{Edited by:}

Luis Enrique Munoz,

Friedrich-Alexander University

Erlangen-Nürnberg, Germany

\section{Reviewed by:}

Patrizia Rovere Querini, Ospedale San Raffaele and Vita-Salute University,

Italy

Luis Enrique Munoz,

Friedrich-Alexander University

Erlangen-Nürnberg, Germany

Christian Beyer, Friedrich-Alexander

University Erlangen-Nuremberg,

Germany

${ }^{*}$ Correspondence:

Noelia A-Gonzalez, Department of Epidemiology, Atherothrombosis and

Imaging, Laboratory of Imaging the

Cardiovascular Inflammation and the

Immune Response, Fundación Centro

Nacional de Investigaciones

Cardiovasculares (CNIC), Calle

Melchor Fernandez Almagro 3,

Madrid 28029, Spain

e-mail:noelia.alonso@cnic.es
Clearance of apoptotic cells by macrophages occurs as a coordinated process to ensure tissue homeostasis. Macrophages play a dual role in this process; first, a rapid and efficient phagocytosis of the dying cells is needed to eliminate uncleared corpses that can promote inflammation. Second, after engulfment, macrophages exhibit an anti-inflammatory phenotype, to avoid unwanted immune reactions against cell components. Several nuclear receptors, including liver $\mathrm{X}$ receptor and proliferator-activated receptor, have been linked to these two important features of macrophages during apoptotic cell clearance. This review outlines the emerging implications of nuclear receptors in the response of macrophages to cell clearance. These include activation of genes implicated in metabolism, to process the additional cellular content provided by the engulfed cells, as well as inflammatory genes, to maintain apoptotic cell clearance as an "immunologically silent" process. Remarkably, genes encoding receptors for the so-called "eat-me" signals are also regulated by activated nuclear receptors after phagocytosis of apoptotic cells, thus enhancing the efficiency of macrophages to clear dead cells.

Keywords: macrophages, nuclear receptors, liver $\mathbf{X}$ receptors, apoptotic cell clearance, inflammation

\section{APOPTOTIC CELL RECOGNITION AND CLEARANCE}

Macrophages are professional phagocytes that clear unwanted cells both in the steady-state and during the resolution phase of the immune response. Phagocytosis of apoptotic cells is crucial for development and reproduction. It is also important for the regulation of the immune system because, unlike other phagocytic processes such as phagocytosis of necrotic cells or bacteria, clearance of apoptotic cells does not lead to a pro-inflammatory response in macrophages (1). Apoptotic cell clearance occurs in four steps: sensing of the apoptotic cell, recognition, engulfment of the corpse, and processing of the engulfed material (2). In the last few years, many novel molecules and signaling pathways have been described as key regulators of these steps. In the first step, recognition of the target cell occurs via the so-called "find-me" signals that are released by the apoptotic cell and promote the migration of the phagocyte (3). Examples of these soluble "findme" signals are the nucleotides ATP and UTP (4), fraktalkine (CX3CL1) (5), and lysophosphatidylcholine (LPC) (6). Apoptotic cells exhibit "eat-me" signals in their surface that are recognized by the phagocyte, either directly or through bridging molecules. The best described "eat-me" signal is phosphatidylserine (PtdSer) exposed in the outer leaflet of the membrane of apoptotic cells (7). Scavenger receptors such as CD36; tyrosine kinases, such as Mertk; or immunoglobulin and mucine domain-containing molecules, such as TIM-4, are membrane receptors that recognize PtdSer (8-10). This recognition may be direct or through soluble factors, such as MFG-E8, Gas6, ProteinS, or the C1q opsonin. The signaling pathways triggered during engulfment then lead to reorganization of the cytoskeleton, and promote internalization of the dying cell (2).

In order to maintain homeostasis, the engulfed material needs to be processed by the phagocyte. When apoptosis occurs, the number of dying cells is typically higher than the number of phagocytes present in the tissue. This disproportion is evident during the resolution phase of inflammation, during the negative selection in the thymus or during germinal center reactions $(9$, 11-14). However, in all these cases very few if any apoptotic cells can be detected because tissue-resident and recruited macrophages are extremely efficient at clearing up all dying cells, and efficiently processing the extra cargo ingested to prevent the generation of an inflammatory response. This processing entails production of anti-inflammatory cytokines, such as IL-10 and TGF- $\beta 1$, which are important to initiate the resolution phase or to maintain the process immunologically silent $(1,15,16)$. In support of this concept, deficiency in the phagocytosis of apoptotic cells is one of the hallmarks of patients with systemic lupus erythematosus (17). However, the transcriptional regulators of the inflammatory routes triggered by apoptotic cell clearance have only recently begun to be elucidated.

In order to maintain a normal metabolic rate the engulfing phagocyte must process the extra metabolites provided by the ingested apoptotic cells, as excessive metabolite accumulation may 
be noxious. Cholesterol efflux is induced in phagocytes by apoptotic cells exposure, and is dependent on phosphatidylserine recognition (18). Expression of genes implicated in cholesterol efflux, such as ATP-binding cassette (ABC) transporter genes, is further up-regulated via activation of nuclear receptors $(15,18-20)$. This metabolic response is thought to maintain cholesterol levels within the phagocyte. However, macrophages generally ingest more than one apoptotic cell and phagocytosis further enhances recognition and engulfment of apoptotic targets $(15,19)$. Thus, the extra load of cellular components within the phagocyte might also have energetic benefits for the cell, as it needs energy to continue phagocytizing more cells. Park and collaborators defined an inverse relationship between mitochondrial membrane potential and phagocytosis, in which macrophages with low mitochondrial membrane potential are prone to engulf apoptotic cells. The authors showed that the mitochondrial membrane potential increases in the phagocyte after engulfment of apoptotic cells, to later return to baseline levels. Restoration of baseline potentials is ensured by Ucp2, a mitochondrial membrane protein whose levels also increase after engulfment. Ucp2 therefore acts as a "sensor" for phagocytosis that, by maintaining the mitochondrial membrane potential at basal levels, allows continued phagocytosis (21).

Nuclear receptors are a superfamily of ligand-activated transcription factors implicated in metabolic and inflammatory pathways (22). Their key roles in macrophage biology led us and others to explore their activity in apoptotic cell clearance. This review discusses the importance of nuclear receptors during the phagocytosis of apoptotic cells. We will emphasize how the processing of apoptotic cells, through regulation of metabolic genes and anti-inflammatory pathways, is essential to maintain homeostasis.

\section{NUCLEAR RECEPTORS AT THE INTERFACE OF METABOLISM AND IMMUNITY}

Nuclear receptors share a highly conserved amino-terminal activation domain, a carboxy-terminal ligand binding domain, a zincfinger DNA-binding domain, and a second activation C-terminal domain (22). Since Mangelsdorf and collaborators first proposed in 1995 a classification of nuclear receptors based on their ligands and DNA-binding modalities (23), several categories have been proposed $(24,25)$. A simplistic classification of two types of nuclear receptors is described in the Nuclear Receptors Signaling Atlas resource, NURSA (for more detailed information visit NURSA website: www.nursa.org). In the type I category, hormone receptors undergo nuclear translocation upon ligand activation and bind as homodimers to inverted DNA repeat sequences. This category includes estrogen, glucocorticoid, progesterone, mineralocorticoid, and androgen receptors. Type II nuclear receptors are retained in the nucleus and bind as heterodimers with a different nuclear receptor, the retinoid X receptors ( $R X R$ ), to direct DNA repeats. Thyroid hormone receptor, Liver X Receptors (LXRs), Peroxisome proliferator-activated receptors (PPARs), or Vitamin D receptors (VDRs), among others, fall into this category. Glucocorticoid receptors, LXRs and PPARs have been linked to the phagocytic capacity and phenotypic polarization of macrophages in vitro (26-29). However, the mechanism by which gene regulation by these nuclear receptors impacts tissue homeostasis in vivo during apoptotic cell clearance is only now starting to be uncovered.

Proliferator-activated receptors are comprised of three isoforms (PPAR $\alpha, \operatorname{PPAR} \gamma$, and PPAR $\delta$ ), and are expressed in multiple cell types and tissues. Their endogenous ligands are lipids, such as unsaturated fatty acids, VLDL, and LDL (22). They are essential for fatty acid metabolism by controlling the expression of genes involved in transport, synthesis, activation, and oxidation of fatty acids (30). PPAR $\alpha$ activity is mostly restricted to the metabolism of fatty acids, although remarkable immune-regulating properties have been attributed to PPAR $\alpha$ due to its capacity to regulate Cpt1, a gene involved in T cell function (31).

$\operatorname{PPAR} \delta$ and $\operatorname{PPAR} \gamma$, like other lipid-activated nuclear receptors, are involved in the regulation of inflammatory genes in macrophages. PPAR $\delta$ is ubiquitously expressed and exhibit pleiotropic functions that range from metabolism, development, and reproduction to inflammation (32). PPAR $\delta$ represses the expression of inflammatory genes through sequestration of the transcriptional repressor BCL-6 (33). It has been implicated in the phagocytosis of apoptotic cells and prevention of systemic autoimmune diseases (19). Analogous functions in apoptotic cell clearance and autoimmune processes have been described for $\operatorname{PPAR} \gamma$ in macrophages (20). Its importance in lipid metabolism is underlined by the variety and function of its target genes, including the scavenger receptor CD36, lipoprotein lipase (LPL), and the nuclear receptor $\operatorname{LXR} \alpha(34,35)$.

$\mathrm{LXR} \alpha$ and LXR $\beta$, the two isoforms of LXR, are physiologically activated by oxidized forms of cholesterol. LXR $\beta$ is ubiquitously expressed, whereas LXR $\alpha$ is expressed mainly in myeloid cells, intestine, adipose tissue, adrenal glands, and liver. Both isoforms regulate a variety of genes implicated in cholesterol efflux, including the $\mathrm{ABC}$ transporters ABCA1 and ABCG1. Accordingly, they have been shown to be important in the prevention of metabolic diseases such as atherosclerosis (22). LXRs can also be pharmacologically activated by potent synthetic agonists that functionally mimic their endogenous ligands.

Elegant studies in the last 10 years have shown that in macrophages previously challenged with inflammatory stimuli, LXRs can act as trans-repressors of pro-inflammatory genes, by binding to other transcription factors and promoting their deactivation (36-39). Thus, like PPARs, LXRs generate cross-talk between inflammation and metabolism. Several studies have now uncovered important roles for these receptors beyond the regulation of inflammatory gene expression and innate immunity. LXR $\beta$ has been implicated in the proliferation of T cells, thus influencing adaptive immunity (40). In addition, we have demonstrated that LXR $\alpha$ is essential for the development of two populations of macrophages in the marginal zone of the spleen that are important for immune responses against T cell-independent antigens (41).

The above described pleiotropic functions of PPARs and LXRs position them as excellent candidates to influence macrophage responses during apoptotic cell clearance, in which regulation of metabolic and inflammatory genes is crucial.

\section{PPARs AND AUTOIMMUNITY}

Initial evidence implicating PPAR $\gamma$ in apoptotic cell clearance was obtained in the context of reactive oxygen species 
(ROS) production by macrophages (27). In PMA-stimulated macrophages, the production of ROS was attenuated when fed with apoptotic cells. This anti-inflammatory effect was linked to the activity of PPAR $\gamma$ after apoptotic cell clearance. Electrophoretic mobility shift assays revealed transient activation of this nuclear receptor after apoptotic cell recognition (27). Although Mukundan and collaborators later showed that PPAR $\gamma$ transcripts in bone marrow-derived macrophages were not regulated upon phagocytosis (19), several subsequent reports have confirmed a role for PPAR $\gamma$ activation in apoptotic cell clearance $(20,42)$. In support of the relevance of PPAR $\gamma$ in apoptotic cell phagocytosis by macrophages in vivo, mice with conditional deficiency in the receptor in macrophages show a delay in phagocytosis of apoptotic cells and develop autoimmune kidney glomerulopathy (20).

Mice deficient in PPAR $\delta$, either globally or restricted to macrophages, also develop a lupus-like autoimmune phenotype characterized by increased levels of autoantibodies in serum and glomerulonephritis (19). This inflammatory phenotype was associated with defective clearance of apoptotic cells by PPAR $\delta$ deficient macrophages. Genomic analysis uncovered a number of target genes that were regulated after phagocytosis in a PPAR $\delta$ dependent manner. These genes included the $\mathrm{Clqb}$ opsonin, which mediates binding of PtdSer to its receptor on the membrane of the phagocyte, and was described as a direct target of PPAR $\delta-R X R \alpha$ heterodimers. Through this mechanism, phagocytosis is promoted by clearance itself, as double feeding experiments demonstrated that macrophages increased their phagocytic capacity following successive rounds of apoptotic cell feeding (19).

Similarly, RXR $\alpha$ - and PPAR $\gamma$-deficient macrophages showed impaired apoptotic cell clearance. In addition, engulfment of apoptotic cells failed to down-regulate inflammatory cytokines in LPS-stimulated macrophages derived from $\operatorname{RXR} \alpha$ - and PPAR $\gamma$ deficient mice. As noted above, these mice develop glomerulopathy and proteinuria, both hallmarks of kidney autoimmune disease (20). As with PPAR $\delta$, the activity of these nuclear receptors is induced after phagocytosis of apoptotic cells, thereby promoting the transcription of genes encoding membrane receptors and opsonins required for further recognition and engulfment of apoptotic cells. These studies underscore the importance of nuclear receptors in phagocytosis, in part by priming the macrophage for continued engulfment of apoptotic targets.

\section{LXRs AND APOPTOTIC CELL CLEARANCE: BEYOND MACROPHAGE HOMEOSTASIS}

In human macrophages, LXR activation regulates the expression of $\operatorname{LXR} \alpha$ (43) and PPAR $\gamma$ (44), thereby creating a positive feedback loop that enhances the phagocytic capacity of macrophages. However, this is not the only role of LXRs in apoptotic cell clearance in human macrophages. Though not a direct target gene of LXR $\alpha$, Transglutaminase 2 ( Tgm-2), which encodes a proteincrosslinking enzyme implicated in the phagocytosis of apoptotic cells (45), is regulated in human macrophages after engulfment of apoptotic targets in an $\operatorname{LXR} \alpha$-dependent manner (29). Together with the activity of PPARs during apoptotic cell clearance, these observations establish LXRs and PPARs as molecules that influence the "appetite" of macrophages.
As described above, LXRs are physiologically activated by oxidized forms of cholesterol and are key regulators of cholesterol metabolism by controlling the expression of genes responsible for cholesterol efflux, such as ABCA1. This raises the question of what is the significance of LXR activation during apoptotic cell clearance. When a macrophage ingests an apoptotic cell, the amount of cellular content within the macrophage significantly increases, and the extra cellular material has to be processed. A potential solution to this dilemma is the up-regulated expression of a gene responsible for cholesterol efflux, Abcal, upon engulfment of apoptotic cells $(18,46)$. LXR activation appears to be required for this upregulation of Abcal because, in peritoneal macrophages obtained from mice deficient in both LXR isoforms ( $\mathrm{LXR} \alpha \beta-/-$ ), changes in Abcal mRNA expression were blunted after apoptotic cell clearance when compared to control macrophages (46). Moreover, Kiss and collaborators demonstrated that Abcal expression and cholesterol efflux were induced upon PtdSer recognition by the macrophage, implying that engulfment is dispensable for LXR activation. In support of a role for nuclear receptors in cholesterol processing, LXRs and PPAR $\gamma$ antagonists inhibited upregulation of $A b c a 1$ and cholesterol efflux mediated by apoptotic cell clearance (18).

At the time of these studies, LXR activation had been exclusively linked to the metabolic response of the phagocyte during apoptotic cell clearance. Using LXR knock-out mice we observed an impaired phagocytic capacity in LXR-deficient macrophages both in vivo and in vitro, and this impairment was associated to the development of autoimmunity in these mice (15). Apoptotic cells promote the expression of a number of genes in macrophages after clearance. Some of these genes are regulated in an LXR-dependent manner, such as genes implicated in cholesterol metabolism, glucose transport, and other genes identified as LXR target genes in other studies. Similarly, the expression of Mertk, a membrane receptor for apoptotic cells, was also up-regulated by LXRs during phagocytosis or after activation with synthetic LXR ligands, and was identified in these studies as a novel direct target of LXR (15). Together, the responses triggered by LXR activation contribute to enhancing recognition and further engagement of apoptotic targets as evidenced by the observation that the phagocytic capacity in $\operatorname{LXR} \alpha \beta-1-$ macrophages does not increase after several rounds of apoptotic cell feeding. Notably, by modulating the expression of inflammation-related genes, LXR also participates in the polarization of the macrophage toward an anti-inflammatory phenotype after engulfment of dying cells. This activity essentially contributes to avoidance of unwanted inflammation, which is illustrated by the lupus-like autoimmune disease developed by $L X R \alpha \beta-/-$ mice as they age (15).

Liver X receptors nuclear receptors have more recently emerged as regulators of neutrophil homeostasis $(47,48)$. Due to their short half-life (estimated in $12.5 \mathrm{~h}$ in mice), neutrophils must be efficiently cleared on a daily basis. LXR-deficient mice display neutrophilia in blood and accumulation of neutrophils in the spleen and liver, a phenotype that was accounted for by the impaired capacity of LXR-deficient macrophages to engulf apoptotic neutrophils. Production of IL-23 by macrophages and dendritic cells is a critical signal that controls the levels of neutrophils in blood by acting upstream of IL-17 and G-CSF (49). Importantly, 
activation of LXRs upon neutrophil engulfment strongly represses IL-23 transcription (47). Extending these studies, we have recently shown that clearance of aged neutrophils in the bone marrow modulates the size and activity of the hematopoietic niche through LXR activation (48). We found that neutrophils cleared from blood enter the bone marrow and are engulfed by macrophages, leading to reductions in the number of niche cells and mobilization of hematopoietic progenitors into the bloodstream. In addition, the transcript levels of LXR target genes in the bone marrow spontaneously increase at the time when neutrophils are cleared in this organ, and mice in which macrophages have been eliminated lacked the normal oscillations in Abcal expression. Further, regulation of niche cells and progenitor release are impaired in LXR-deficient mice. Together, these findings uncovered new functions for the homeostatic clearance of dying cells in regulating hematopoietic niches in the bone marrow, and a central role for LXR receptors in coordinating these functions (48).

These recent advances in the field provide examples of the multitude of processes and tissues that are likely regulated by the clearance of apoptotic cells by macrophages, and by the receptors involved in this fundamental process.

\section{FUTURE DIRECTIONS}

Liver $\mathrm{X}$ receptors and PPARs are now recognized regulators of the anti-inflammatory response in macrophages after clearance of apoptotic cells. Moreover, these receptors are key players in the recognition and engagement of apoptotic cells by further enhancing phagocytosis through transcriptional regulation of various receptors and bridging molecules. The exact pathways by which LXRs and PPARs are activated during the phagocytosis of apoptotic cells remain an open question in the field (Figure 1). We and others postulated that lipids derived from the engulfed cell might provide ligands for PPARs and LXRs, as demonstrated by the lack of LXR activation when macrophages are fed with sterolfree apoptotic thymocytes (15). Because recognition of PtdSer by macrophages is sufficient to activate an LXR-dependent metabolic program without engulfment (18), additional routes of recognition and engulfment can activate these nuclear receptors.

These novel roles of lipid-activated nuclear receptors in phagocytosis of apoptotic cells raise an interesting issue regarding cell metabolism and bioenergetics. The enhancement of phagocytosis of apoptotic cells mediated by nuclear receptors, might respond to a necessity of generating more energy to continue phagocytizing. Mitochondria provide the majority of the energy supply by oxidative phosphorylation in the respiratory chain. In fact, macrophages with low mitochondrial membrane potential are more prone to phagocyte apoptotic cells (21). Whether nuclear receptors and mitochondria cross-talk during apoptotic cell clearance to enhance phagocytosis arises as an interesting possibility. Supporting this idea, the activity of several nuclear receptors have been defined

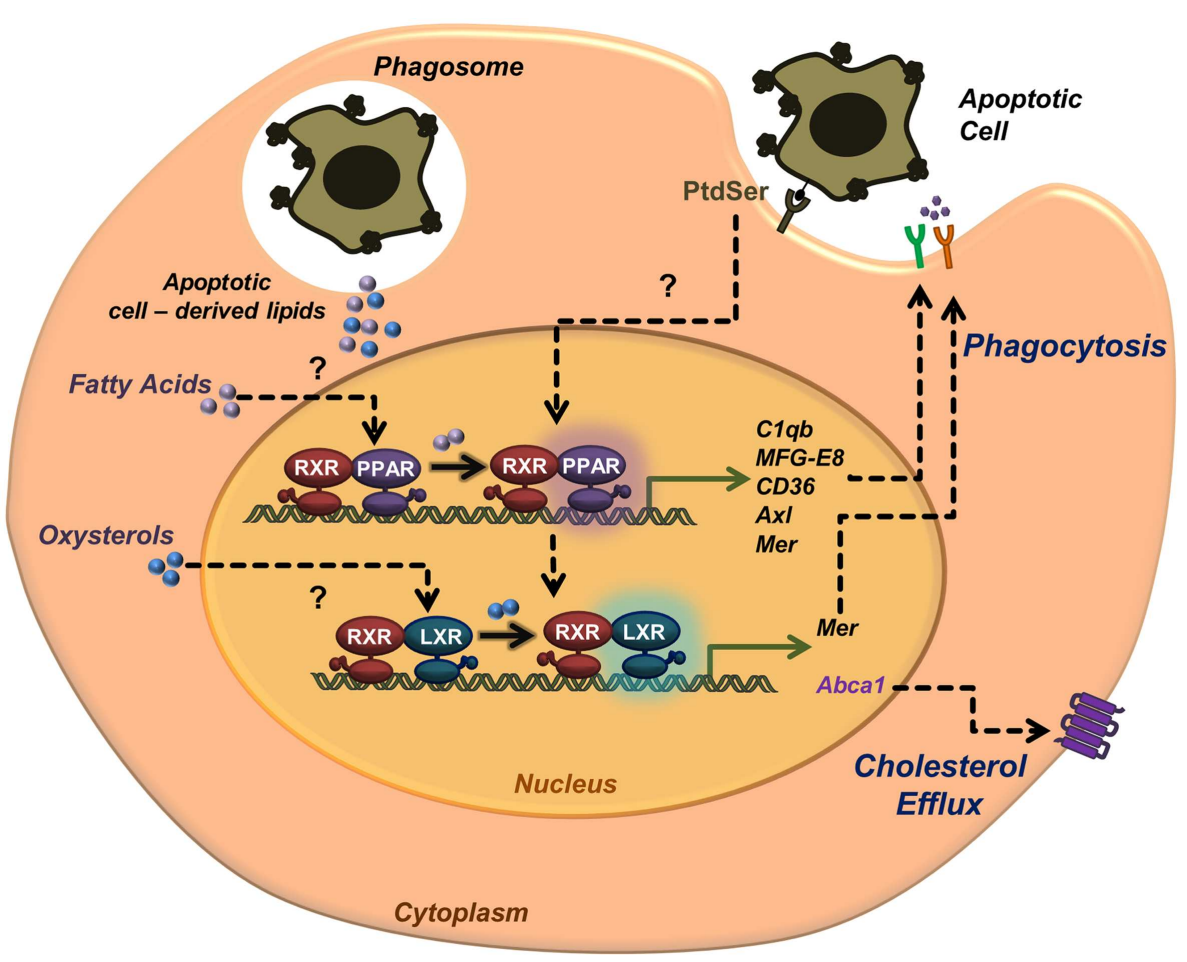

FIGURE 1 | Activation of nuclear receptors in phagocytes during apoptotic cell clearance. Apoptotic cell recognition and engulfment promote the transcriptional activity of nuclear receptors LXRs and PPARs. Recognition of phosphatidylserine in the outer leaflet membrane of the apoptotic cell leads to transcriptional activation of ABCA1 and cholesterol efflux. Nuclear receptor activation upon apoptotic cell phagocytosis also leads to upregulation of phagocytic receptors (e.g., Mer, CD36, and Axl) and opsonins (e.g., MFG-E8 and C1qb). Lipids derived from the engulfed apoptotic cells may also serve as source of endogenous ligands to activate PPARs (fatty acids) and LXRs (oxysterols). 
in mitochondria, regulating gene expression, coordinated with nuclear gene expression, in situations of high energy demand (50). For example, PPAR $\gamma$ co-activator $1 \alpha$, PGC- $1 \alpha$, collaborates with PPARs to regulate expression of mitochondrial enzymes involved in fatty acid transport and oxidation (51). However, the specific role of nuclear receptors in mitochondrial metabolism during apoptotic cell clearance remains unclear.

An important outcome of this research topic will be the potential therapeutic implications of apoptotic cell clearance in a wide range of inflammatory and metabolic diseases. It has been shown that enhancing engulfment of apoptotic neutrophils in situ accelerates the resolution of bacterial infection and lung inflammation (52-54). However, the exogenous administration of apoptotic cells could also lead to autoimmunity, so the therapeutic approaches need to be finely controlled to avoid deleterious effects (55). Targeting nuclear receptors by activation through synthetic ligands, have been proven to ameliorate inflammation in mouse models of autoimmunity (15) and atherosclerosis (56). Though some PPAR agonists have already been approved for clinical use to treat metabolic diseases, a better understanding of nuclear receptor activation during apoptotic cell clearance may pave the way for the development of novel treatments for infectious, inflammatory, and metabolic diseases.

\section{ACKNOWLEDGMENTS}

Both authors contributed to the writing and editing of this review. We thank Linnea A. Weiss, María Casanova-Acebes, and Jose Angel Nicolas for critical comments on the manuscript. This mini-review was supported by grant SAF2012-31142 from the Spanish Ministry of Economy and Competitivity (MINECO) to Andrés Hidalgo, the Juan de la Cierva program (JCI-2012-12659) from MINECO to Noelia A-Gonzalez, and the FP7-People-IRG Program (246655) to Andrés Hidalgo. The Centro Nacional de Investigaciones Cardiovasculares is supported by MINECO and the Pro-CNIC Foundation.

\section{REFERENCES}

1. Henson PM. Dampening inflammation. Nat Immunol (2005) 6(12):1179-81. doi:10.1038/ni1205-1179

2. Hochreiter-Hufford A, Ravichandran KS. Clearing the dead: apoptotic cell sensing, recognition, engulfment, and digestion. Cold Spring Harb Perspect Biol (2013) 5(1):a008748. doi:10.1101/cshperspect.a008748

3. Ravichandran KS. Beginnings of a good apoptotic meal: the find-me and eatme signaling pathways. Immunity (2011) 35(4):445-55. doi:10.1016/j.immuni. 2011.09.004

4. Elliott MR, Chekeni FB, Trampont PC, Lazarowski ER, Kadl A, Walk SF, et al. Nucleotides released by apoptotic cells act as a find-me signal to promote phagocytic clearance. Nature (2009) 461(7261):282-6. doi:10.1038/nature08296

5. Truman LA, Ford CA, Pasikowska M, Pound JD, Wilkinson SJ, Dumitriu IE, et al. CX3CL1/fractalkine is released from apoptotic lymphocytes to stimulate macrophage chemotaxis. Blood (2008) 112(13):5026-36. doi:10.1182/blood2008-06-162404

6. Lauber K, Bohn E, Krober SM, Xiao YJ, Blumenthal SG, Lindemann RK, et al. Apoptotic cells induce migration of phagocytes via caspase-3-mediated release of a lipid attraction signal. Cell (2003) 113(6):717-30. doi:10.1016/S00928674(03)00422-7

7. Fadok VA, Voelker DR, Campbell PA, Cohen JJ, Bratton DL, Henson PM. Exposure of phosphatidylserine on the surface of apoptotic lymphocytes triggers specific recognition and removal by macrophages. J Immunol (1992) 148(7):2207-16.
8. Scott RS, McMahon EJ, Pop SM, Reap EA, Caricchio R, Cohen PL, et al. Phagocytosis and clearance of apoptotic cells is mediated by MER. Nature (2001) 411(6834):207-11. doi:10.1038/35079659

9. Rodriguez-Manzanet R, Sanjuan MA, Wu HY, Quintana FJ, Xiao S, Anderson $\mathrm{AC}$, et al. T and B cell hyperactivity and autoimmunity associated with nichespecific defects in apoptotic body clearance in TIM-4-deficient mice. Proc Natl Acad Sci U S A (2010) 107(19):8706-11. doi:10.1073/pnas.0910359107

10. Nagata S, Hanayama R, Kawane K. Autoimmunity and the clearance of dead cells. Cell (2010) 140(5):619-30. doi:10.1016/j.cell.2010.02.014

11. Surh CD, Sprent J. T-cell apoptosis detected in situ during positive and negative selection in the thymus. Nature (1994) 372(6501):100-3. doi:10.1038/372100a0

12. Fadok VA, Bratton DL, Konowal A, Freed PW, Westcott JY, Henson PM. Macrophages that have ingested apoptotic cells in vitro inhibit proinflammatory cytokine production through autocrine/paracrine mechanisms involving TGF-beta, PGE2, and PAF. J Clin Invest (1998) 101(4):890-8. doi:10.1172/ JCI1112

13. Cohen PL, Caricchio R, Abraham V, Camenisch TD, Jennette JC, Roubey RA, et al. Delayed apoptotic cell clearance and lupus-like autoimmunity in mice lacking the c-mer membrane tyrosine kinase. J Exp Med (2002) 196(1):135-40. doi:10.1084/jem.20012094

14. Hanayama R, Tanaka M, Miyasaka K, Aozasa K, Koike M, Uchiyama Y, et al. Autoimmune disease and impaired uptake of apoptotic cells in MFG-E8deficient mice. Science (2004) 304(5674):1147-50. doi:10.1126/science.1094359

15. A-Gonzalez N, Bensinger SJ, Hong C, Beceiro S, Bradley MN, Zelcer N, et al. Apoptotic cells promote their own clearance and immune tolerance through activation of the nuclear receptor LXR. Immunity (2009) 31(2):245-58. doi:10.1016/j.immuni.2009.06.018

16. Elliott MR, Ravichandran KS. Clearance of apoptotic cells: implications in health and disease. J Cell Biol (2010) 189(7):1059-70. doi:10.1083/jcb.201004096

17. Janko C, Schorn C, Grossmayer GE, Frey B, Herrmann M, Gaipl US, et al. Inflammatory clearance of apoptotic remnants in systemic lupus erythematosus (SLE). Autoimmun Rev (2008) 8(1):9-12. doi:10.1016/j.autrev.2008.07.015

18. Kiss RS, Elliott MR, Ma Z, Marcel YL, Ravichandran KS. Apoptotic cells induce a phosphatidylserine-dependent homeostatic response from phagocytes. Curr Biol (2006) 16(22):2252-8. doi:10.1016/j.cub.2006.09.043

19. Mukundan L, Odegaard JI, Morel CR, Heredia JE, Mwangi JW, Ricardo-Gonzalez RR, et al. PPAR-delta senses and orchestrates clearance of apoptotic cells to promote tolerance. Nat Med (2009) 15(11):1266-72. doi:10.1038/nm.2048

20. Roszer T, Menendez-Gutierrez MP, Lefterova MI, Alameda D, Nunez V, Lazar MA, et al. Autoimmune kidney disease and impaired engulfment of apoptotic cells in mice with macrophage peroxisome proliferator-activated receptor gamma or retinoid X receptor alpha deficiency. J Immunol (2011) 186(1):621-31. doi:10.4049/jimmunol.1002230

21. Park D, Han CZ, Elliott MR, Kinchen JM, Trampont PC, Das S, et al. Continued clearance of apoptotic cells critically depends on the phagocyte Ucp2 protein. Nature (2011) 477(7363):220-4. doi:10.1038/nature10340

22. Castrillo A, Tontonoz P. Nuclear receptors in macrophage biology: at the crossroads of lipid metabolism and inflammation. Annu Rev Cell Dev Biol (2004) 20:455-80. doi:10.1146/annurev.cellbio.20.012103.134432

23. Mangelsdorf DJ, Thummel C, Beato M, Herrlich P, Schutz G, Umesono K, et al. The nuclear receptor superfamily: the second decade. Cell (1995) 83(6):835-9. doi:10.1016/0092-8674(95)90199-X

24. Kidani Y, Bensinger SJ. Liver X receptor and peroxisome proliferator-activated receptor as integrators of lipid homeostasis and immunity. Immunol Rev (2012) 249(1):72-83. doi:10.1111/j.1600-065X.2012.01153.x

25. Olefsky JM. Nuclear receptor minireview series. J Biol Chem (2001) 276(40):36863-4. doi:10.1074/jbc.R100047200

26. Liu Y, Cousin JM, Hughes J, Van Damme J, Seckl JR, Haslett C, et al. Glucocorticoids promote nonphlogistic phagocytosis of apoptotic leukocytes. J Immunol (1999) 162(6):3639-46.

27. Johann AM, von Knethen A, Lindemann D, Brune B. Recognition of apoptotic cells by macrophages activates the peroxisome proliferator-activated receptor-gamma and attenuates the oxidative burst. Cell Death Differ (2006) 13(9):1533-40. doi:10.1038/sj.cdd.4401832

28. Majai G, Sarang Z, Csomos K, Zahuczky G, Fesus L. PPARgamma-dependent regulation of human macrophages in phagocytosis of apoptotic cells. Eur J Immunol (2007) 37(5):1343-54. doi:10.1002/eji.200636398

29. Rebe C, Raveneau M, Chevriaux A, Lakomy D, Sberna AL, Costa A, et al. Induction of transglutaminase 2 by a liver $\mathrm{X}$ receptor/retinoic acid receptor alpha 
pathway increases the clearance of apoptotic cells by human macrophages. Circ Res (2009) 105(4):393-401. doi:10.1161/CIRCRESAHA.109.201855

30. Desvergne B, Wahli W. Peroxisome proliferator-activated receptors: nuclear control of metabolism. Endocr Rev (1999) 20(5):649-88. doi:10.1210/edrv.20.5. 0380

31. van der Windt GJ, Everts B, Chang CH, Curtis JD, Freitas TC, Amiel E, et al. Mitochondrial respiratory capacity is a critical regulator of CD8+ T cell memory development. Immunity (2012) 36(1):68-78. doi:10.1016/j.immuni.2011. 12.007

32. Lee CH, Chawla A, Urbiztondo N, Liao D, Boisvert WA, Evans RM, et al. Transcriptional repression of atherogenic inflammation: modulation by PPARdelta. Science (2003) 302(5644):453-7. doi:10.1126/science.1087344

33. Takata Y, Liu J, Yin F, Collins AR, Lyon CJ, Lee CH, et al. PPARdelta-mediated antiinflammatory mechanisms inhibit angiotensin II-accelerated atherosclerosis. Proc Natl Acad Sci U S A (2008) 105(11):4277-82. doi:10.1073/pnas. 0708647105

34. Chawla A, Boisvert WA, Lee CH, Laffitte BA, Barak Y, Joseph SB, et al. A PPAR gamma-LXR-ABCA1 pathway in macrophages is involved in cholesterol efflux and atherogenesis. Mol Cell (2001) 7(1):161-71. doi:10.1016/S1097-2765(01) 00164-2

35. Tontonoz P, Nagy L, Alvarez JG, Thomazy VA, Evans RM. PPARgamma promotes monocyte/macrophage differentiation and uptake of oxidized LDL. Cell (1998) 93(2):241-52. doi:10.1016/S0092-8674(00)81575-5

36. Castrillo A, Joseph SB, Marathe C, Mangelsdorf DJ, Tontonoz P. Liver X receptordependent repression of matrix metalloproteinase-9 expression in macrophages. J Biol Chem (2003) 278(12):10443-9. doi:10.1074/jbc.M213071200

37. Castrillo A, Joseph SB, Vaidya SA, Haberland M, Fogelman AM, Cheng G, et al. Crosstalk between LXR and toll-like receptor signaling mediates bacterial and viral antagonism of cholesterol metabolism. Mol Cell (2003) 12(4):805-16. doi:10.1016/S1097-2765(03)00384-8

38. Joseph SB, Castrillo A, Laffitte BA, Mangelsdorf DJ, Tontonoz P. Reciprocal regulation of inflammation and lipid metabolism by liver X receptors. Nat Med (2003) 9(2):213-9. doi:10.1038/nm820

39. Marathe C, Bradley MN, Hong C, Lopez F, Ruiz de Galarreta CM, Tontonoz $\mathrm{P}$, et al. The arginase II gene is an anti-inflammatory target of liver $\mathrm{X}$ receptor in macrophages. J Biol Chem (2006) 281(43):32197-206. doi:10.1074/jbc. M605237200

40. Bensinger SJ, Bradley MN, Joseph SB, Zelcer N, Janssen EM, Hausner MA, et al. LXR signaling couples sterol metabolism to proliferation in the acquired immune response. Cell (2008) 134(1):97-111. doi:10.1016/j.cell.2008.04.052

41. A-Gonzalez N, Guillen JA, Gallardo G, Diaz M, de la Rosa JV, Hernandez IH, et al. The nuclear receptor LXRalpha controls the functional specialization of splenic macrophages. Nat Immunol (2013) 14(8):831-9. doi:10.1038/ni.2622

42. von Knethen A, Sha LK, Kuchler L, Heeg AK, Fuhrmann D, Heide H, et al. 5-Lipoxygenase contributes to PPARgamma activation in macrophages in response to apoptotic cells. Cell Signal (2013) 25(12):2762-8. doi:10.1016/j. cellsig.2013.08.045

43. Laffitte BA, Joseph SB, Walczak R, Pei L, Wilpitz DC, Collins JL, et al. Autoregulation of the human liver X receptor alpha promoter. Mol Cell Biol (2001) 21(22):7558-68. doi:10.1128/MCB.21.22.7558-7568.2001

44. Seo JB, Moon HM, Kim WS, Lee YS, Jeong HW, Yoo EJ, et al. Activated liver $\mathrm{X}$ receptors stimulate adipocyte differentiation through induction of peroxisome proliferator-activated receptor gamma expression. Mol Cell Biol (2004) 24(8):3430-44. doi:10.1128/MCB.24.8.3430-3444.2004

45. Szondy Z, Sarang Z, Molnar P, Nemeth T, Piacentini M, Mastroberardino PG, et al. Transglutaminase $2-1-$ mice reveal a phagocytosis-associated crosstalk between macrophages and apoptotic cells. Proc Natl Acad Sci U S A (2003) 100(13):7812-7. doi:10.1073/pnas.0832466100
46. Gerbod-Giannone MC, Li Y, Holleboom A, Han S, Hsu LC, Tabas I, et al. TNFalpha induces ABCA1 through NF-kappaB in macrophages and in phagocytes ingesting apoptotic cells. Proc Natl Acad Sci U S A (2006) 103(9):3112-7. doi:10.1073/pnas.0510345103

47. Hong C, Kidani Y, A-Gonzalez N, Phung T, Ito A, Rong X, et al. Coordinate regulation of neutrophil homeostasis by liver $\mathrm{X}$ receptors in mice. J Clin Invest (2012) 122(1):337-47. doi:10.1172/JCI58393

48. Casanova-Acebes M, Pitaval C, Weiss LA, Nombela-Arrieta C, Chevre R, AGonzalez N, et al. Rhythmic modulation of the hematopoietic niche through neutrophil clearance. Cell (2013) 153(5):1025-35. doi:10.1016/j.cell.2013.04. 040

49. Stark MA, Huo Y, Burcin TL, Morris MA, Olson TS, Ley K. Phagocytosis of apoptotic neutrophils regulates granulopoiesis via IL-23 and IL-17. Immunity (2005) 22(3):285-94. doi:10.1016/j.immuni.2005.01.011

50. Psarra AM, Sekeris CE. Nuclear receptors and other nuclear transcription factors in mitochondria: regulatory molecules in a new environment. Biochim Biophys Acta (2008) 1783(1):1-11. doi:10.1016/j.bbamcr.2007.10.021

51. Vega RB, Huss JM, Kelly DP. The coactivator PGC-1 cooperates with peroxisome proliferator-activated receptor alpha in transcriptional control of nuclear genes encoding mitochondrial fatty acid oxidation enzymes. Mol Cell Biol (2000) 20(5):1868-76. doi:10.1128/MCB.20.5.1868-1876.2000

52. Lucas CD, Allen KC, Dorward DA, Hoodless LJ, Melrose LA, Marwick JA, et al. Flavones induce neutrophil apoptosis by down-regulation of Mcl-1 via a proteasomal-dependent pathway. FASEB J (2013) 27(3):1084-94. doi:10.1096/ fi. $12-218990$

53. Lucas CD, Dorward DA, Tait MA, Fox S, Marwick JA, Allen KC, et al. Downregulation of Mcl-1 has anti-inflammatory pro-resolution effects and enhances bacterial clearance from the lung. Mucosal Immunol (2013). doi:10.1038/mi. 2013.102

54. McGrath EE, Marriott HM, Lawrie A, Francis SE, Sabroe I, Renshaw SA, et al. TNF-related apoptosis-inducing ligand (TRAIL) regulates inflammatory neutrophil apoptosis and enhances resolution of inflammation. J Leukoc Biol (2011) 90(5):855-65. doi:10.1189/jlb.0211062

55. Poon IK, Lucas CD, Rossi AG, Ravichandran KS. Apoptotic cell clearance: basic biology and therapeutic potential. Nat Rev Immunol (2014) 14(3):166-80. doi: $10.1038 /$ nri3607

56. Vucic E, Calcagno C, Dickson SD, Rudd JH, Hayashi K, Bucerius J, et al. Regression of inflammation in atherosclerosis by the LXR agonist R211945: a noninvasive assessment and comparison with atorvastatin. JACC Cardiovasc Imaging (2012) 5(8):819-28. doi:10.1016/j.jcmg.2011.11.025

Conflict of Interest Statement: The authors declare that the research was conducted in the absence of any commercial or financial relationships that could be construed as a potential conflict of interest.

Received: 25 February 2014; accepted: 28 April 2014; published online: 12 May 2014. Citation: A-Gonzalez N and Hidalgo A (2014) Nuclear receptors and clearance of apoptotic cells: stimulating the macrophage's appetite. Front. Immunol. 5:211. doi: 10.3389/fimmu.2014.00211

This article was submitted to Inflammation, a section of the journal Frontiers in Immunology.

Copyright $\odot 2014$ A-Gonzalez and Hidalgo. This is an open-access article distributed under the terms of the Creative Commons Attribution License (CC BY). The use, distribution or reproduction in other forums is permitted, provided the original author(s) or licensor are credited and that the original publication in this journal is cited, in accordance with accepted academic practice. No use, distribution or reproduction is permitted which does not comply with these terms. 